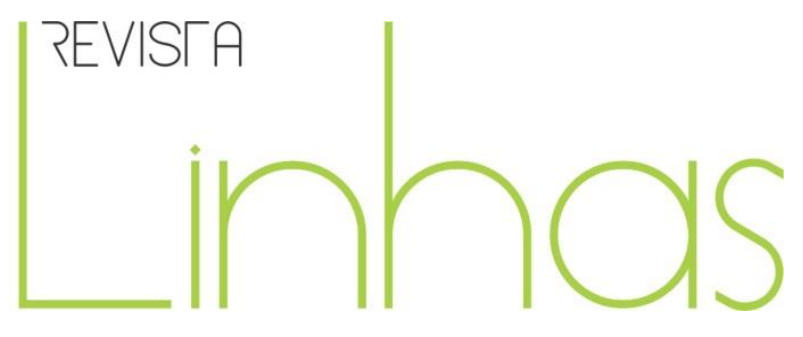

\title{
Resenha do livro "Livro, leitura e bibliotecas em tempos sombrios"
}

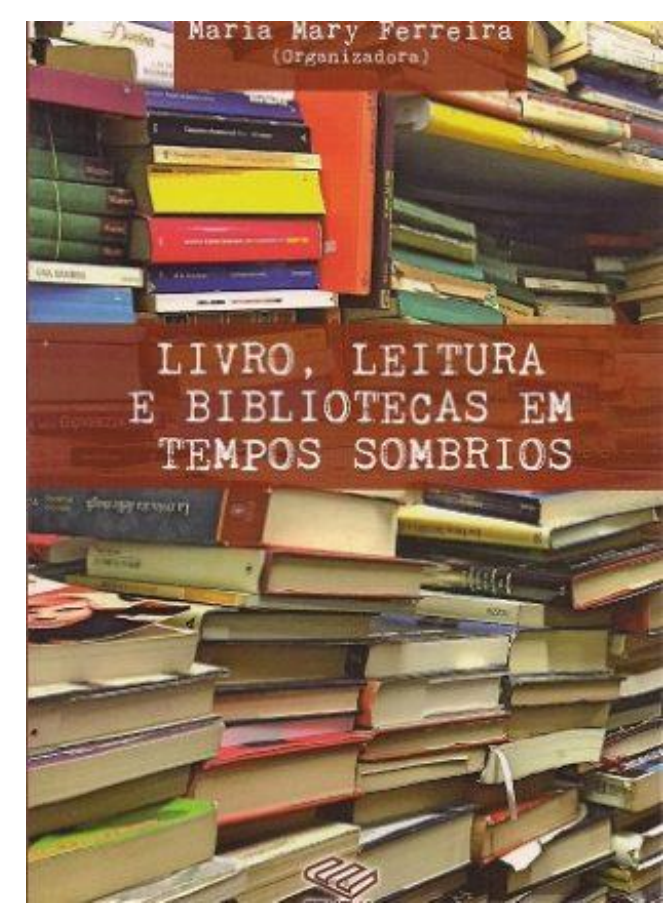

FERREIRA, Maria Mary et al. (org.). Livro, leitura e bibliotecas em tempos sombrios. São Luís: UFMA, 2017.

\section{José Augusto da Silva Neto}

Universidade do Estado de Santa Catarina - UDESC - Brasil

neto.biblio@gmail.com

\section{Para citar esta resenha:}

SILVA NETO, José Augusto da. Resenha do livro "Livro, leitura e bibliotecas em tempos sombrios". Revista Linhas. Florianópolis, v. 22, n. 49, p. 427-432, maio/ago. 2021. 
O momento político-social que o Brasil vivencia nos cerca de incertezas. Incertezas essas que circundam o nosso dia a dia, fazendo parte diretamente do nosso convívio em sociedade. O título resenhado trata de dúvidas voltadas para o universo que compreende o livro, a leitura e as bibliotecas, abordando também, questões que correspondem à angústia que é dialogar sobre cultura e educação em tempos sombrios. Essa obra contém oito autores no total, responsáveis pela escrita de nove artigos, contando com a organizadora, Maria Mary Ferreira, autora de dois desses artigos, incluindo o texto que faz a introdução do livro. O prefácio fica sob a responsabilidade de Aldinar Martins Bottentuit.

Maria Mary Ferreira é professora do Departamento de Biblioteconomia e do Programa de Pós-Graduação em Políticas Públicas da Universidade Federal do Maranhão (UFMA). É graduada em Biblioteconomia pela UFMA, mestre em Políticas Públicas pela mesma universidade, doutora em Sociologia pela Universidade Estadual Paulista (Unesp), com estágio doutoral na Universidade de Coimbra, em Portugal. É organizadora de diversas publicações, entre elas: Mulher, gênero e políticas públicas (1999) e Políticas públicas de gênero: o pensar e o fazer em Imperatriz (2014). Foi diretora da Biblioteca Pública Benedito Leite (1991-1993) e secretária adjunta de Cultura do Maranhão (2007).

Aldinar Martins Bottentuit nos mostra, por meio de um convidativo prefácio, de onde surgiram tais reflexões para a composição do livro, as quais foram resultados dos debates realizados no VIII e no IX Seminário de Políticas Públicas de Bibliotecas, Leitura e Informação; uma iniciativa do Núcleo de Estudos e Pesquisas de Políticas Públicas de Informação, Leitura e Cidadania, em conjunto com professores do Departamento de Biblioteconomia e o Programa de Educação (PET), todos pertencentes à UFMA. Bottentuit é bibliotecária formada para UFMA, com mestrado em Ciência da Informação pela Universidade de Brasília (UnB) e doutorado em Ciência da Informação pela Unesp. Assim como os autores que compõem o livro, possui experiência com temáticas de acesso à informação, políticas editoriais, direito das mulheres, entre outras do campo da Biblioteconomia e Ciência da Informação. Apresentadas a organizadora e a autora do prefácio, entramos agora diretamente no conteúdo que se trata os artigos apresentados no livro.

Num diálogo entre a Biblioteconomia e outras áreas das Ciências Humanas e Ciências Sociais Aplicadas, pode-se afirmar que se trata de um trabalho interdisciplinar 
envolvendo diversos aspectos do campo científico. Publicada pela editora da Universidade Federal do Maranhão, o livro tem como objetivo suscitar o debate acadêmico acerca do impeachment votado no congresso em 2016 e quais foram os impactos que essa ação acarretou nas políticas públicas de fomento ao livro, à leitura, às bibliotecas e à cultura no geral. O quadro que se desenhou na perspectiva da cultura pós-impeachment foi de um mal-estar no Ministério da Cultura com saídas de ministros e dúvidas em relação às políticas públicas que vinham sendo implantadas e mantidas no governo de Dilma Rousseff.

É nesse ambiente que são escritos os artigos que compõem o livro, fazendo o leitor (em especial, os profissionais que tenham a leitura como objeto de trabalho, como bibliotecários, professores, estudantes, livreiros e sociedade em geral) refletir sobre esse contexto. Textos nos quais se espera que possam contribuir para reações e pressões quanto ao quadro de desmonte das políticas conquistadas nos dois governos que compreendem os anos de 2003-2015 (FERREIRA, 2017). A capa do livro mostra uma estante repleta de livros, convidando o leitor a adentrar nesse universo e debruçar-se sobre os diálogos que compõem a história dos livros, da leitura e das bibliotecas no Brasil.

Nesse contexto, o livro carrega o título de Livro, leitura e bibliotecas em tempos sombrios, fruto das reflexões e dos debates realizados no Seminário citado anteriormente. Remetendo-me a Roger Chartier (1999), em seu texto A ordem dos livros: leitores autores e bibliotecas na Europa entre os séculos XIV e XVIII, o autor reflete sobre a autoria dos livros e considera que os autores não escrevem livros, e sim textos que se tornam objetos escritos, manuscritos, gravados, impressos e hoje informatizados, quando podemos ler esse mesmo livro em um formato digital (e-book). Todos os textos abordam a biblioteconomia, o livro e a informação como campo do conhecimento, ancorados nas práticas cotidianas vivenciadas pelos autores.

Após esse cenário, como está divido o livro? Ferreira (2017) nos explica, no encerramento da obra, que a temática está dividida em dois capítulos: o primeiro, de cunho mais reflexivo, aborda as questões do livro e a leitura, assim como as muitas formas de interdição e resistência. O segundo capítulo, de uma abordagem mais prática, reflete sobre as políticas de biblioteca e arquivos. Em todos eles, os autores levam os leitores a pensarem sobre a atual conjuntura política, criticando o novo governo vigente e o sensível momento pelo qual o país atravessa, demonstrando certa preocupação, por ora até incisiva, porém 
necessária, para que desperte no leitor a necessidade da crítica e debate sobre o assunto. Além da angústia, há também muita esperança e vontade de construir pontes entre os amantes da leitura, livros e bibliotecas, a fim de superarem esses tempos de incertezas para o país, os tempos sombrios, fazendo alusão ao título de Hanna Arendt, Homens em Tempos Sombrios.

Do que se trata o conteúdo dos artigos? Como citado anteriormente, os primeiros cinco artigos que compõem o primeiro capítulo do livro, com a introdução, focam na reflexão sobre a conjuntura atual por meio de estudos com conteúdos empíricos pautados na história da leitura e revisão bibliográfica de autores consagrados dentro do universo que compreende as ciências humanas. A introdução inicia o debate sobre o desmonte das políticas públicas que abrangem os livros e as bibliotecas, contextualizando o leitor em um recorte temporal pós-ditatura militar, com ressonâncias nas perseguições de intelectuais e escritores no período de Getúlio Vargas até 2016, e apresenta um pouco dos autores que contribuirão com a obra.

O primeiro artigo do primeiro capítulo é de contextualização e reflexão, no qual o autor José Castilho Marques Neto, pautado na filosofia, convida-nos a debater sobre os tempos sombrios vividos desde o golpe. O segundo artigo, de José Henrique de Paula Borralho, é um estudo de abordagem histórica, tendo como objeto o livro e o conhecimento, o qual é adquirido por meio de sua leitura, abordando a censura e a resistência, fazendo um estudo de caso do Maranhão colonial. O terceiro artigo, de Rosenwerk Estrela Santos, tem como temática uma questão atual e interessante para pensarmos as práticas de leitura: trata do livro como prática de liberdade e inclusão social, um estudo também no Maranhão, abordando a juventude de periferia e a formação dos seres para si no movimento hip hop, trabalhando a importância da leitura na constituição cultural e poética que o livro pode ter para o leitor. O quarto artigo, de Felipe Lindoso, aborda o livro e a leitura para a construção de uma cidade livre e a importância que esse tema tem para o desenvolvimento de uma cidade verdadeiramente democrática. O quinto artigo, de autoria da organizadora, traz a reflexão ao campo da biblioteconomia sobre a importância do livro e da leitura, fazendo um coerente diálogo com os autores clássicos que contribuíram na formação política da autora. 
O segundo capítulo, como demonstra Ferreira (2017), aborda as questões reflexivas às bibliotecas e aos arquivos, sendo composto por três artigos. O primeiro, de Carlos Wellington Soares Martins, aborda questões importantes para refletirmos sobre o desmonte das políticas públicas, por meio de dados concretos compreendendo o livro, a leitura e as bibliotecas no governo interino de Michel Temer. O segundo artigo também trabalha a questão do desmonte das políticas de cultura no Brasil, mas com foco nas bibliotecas escolares, principalmente as públicas, de autoria de Maria da Glória Serra Pinto de Alencar. O último texto, de Dirlene Santos Barros, também apresenta muitos dados, discutindo as políticas públicas de informação no Brasil, no contexto do Maranhão, compreendendo as ações desempenhadas pelo Arquivo Público do estado do Maranhão.

O livro nos convida a esse debate entre diversos campos do conhecimento em torno da conversa sobre leitura, livros e bibliotecas. A conjuntura, no período em que foi escrita a obra, instiga-nos a continuar o diálogo e a luta por dias melhores, pois, se em 2017 já havia esse desmonte nas políticas públicas de incentivo à cultura e educação, o quadro que tínhamos em 2019 se desenhava ainda mais grave, de mais desmonte e requeria maior organização por parte de nós, profissionais empenhados com a área.

Nesse contexto, o que cabe a nós como historiadores da educação? Um dos autores mais referenciados no livro, Paulo Freire (2019), mostra-nos o caminho para uma educação como prática libertadora. A obra tem esta intenção: de nos alertar ao debate e, por meio da práxis, nos unir, pelo livro, pela leitura e pelas bibliotecas em tempos sombrios. 
ARENDT, Hannah. Homens em tempos sombrios. São Paulo: Companhia das Letras, 1987. 249p.

CHARTIER, Roger. A ordem dos livros: Leitores, autores e bibliotecas na Europa entre os séculos XIV e XVIII. Brasília: Unb, 1999. 111 p. Tradução de Mary Del Priori.

FREIRE, Paulo. Pedagogia do oprimido. 6. ed. Rio de Janeiro: Paz e Terra, 2019. 251 p.

Recebido em: 19/08/2020

Aprovado em: 28/10/2020

Universidade do Estado de Santa Catarina - UDESC Programa de Pós-Graduação em Educação - PPGE

Revista Linhas

Volume 22 - Número 49 - Ano 2021

revistalinhas@gmail.com 